\title{
PRESIDENTIAL ADDRESS PUBLIC HEALTH INTERVENTIONS THEN AND NOW- HOW THEY WILL SHAPE THE FUTURE HEALTH SYSTEM IN SRI LANKA
}

Dr. P.G.Mahipala*

As human beings, our health is a matter of daily concern. Regardless of age, socioeconomic or ethnic background, we consider health to be our most basic and essential asset. Health, one of the highest aspirations of man, does not exist in isolation. It is related to and influenced by a complex of environmental, social and economic factors ultimately related to each other.

I intend to describe some important public health interventions that have had significant impact on global health and how these have affected our country. Significant milestones in the history of health development in Sri Lanka would be relevant to this topic and will discuss how Sri Lanka may adopt selected internationally recommended public health interventions to strengthen health service delivery for the future.

The WHO's constitution which was first articulated in 1946, defines health as a state of complete physical, mental and social wellbeing and not merely the absence of disease or infirmity. The enjoyment of the highest attainable standard of health is one of the fundamental rights of every human being without distinction of race, religion, political belief, economic or social condition.

The right to health has few key dimensions.

Firstly "The right to health is an inclusive right" This includes a wide range of factors that can help us lead a healthy life. Secondly, the right to health contains freedom. This freedom includes the right to be free from non consensual medical treatment, such as medical experiments and research or forced sterilization. Thirdly, the right to health containing entitlements. Fourthly, health services goods and facilities must be available, accessible, acceptable and of good quality.

The right to health is not the same as the right to be healthy. A common misconception is that the state has to guarantee us good health. However, good health is influenced by several factors that are outside the direct control of states, such as an individual's biological makeup and socio economic conditions. Throughout, history, humanity has been challenged by outbreaks of infectious diseases and other health emergencies that have caused death on unprecedented levels and threatened public health security with no better solution than wait until the epidemic ran its course. However, with time scientific knowledge evolved, containment measures became more sophisticated and some infectious disease outbreaks were gradually brought under control with improved sanitation and the discovery of vaccines. However, microbial organisms are well equipped to invade new territories, adapt to new ecological niches or hosts, change their virulence or modes of transmission and develop resistance to drugs

\section{History/ Landmarks}

As highlighted by Milan La, quote "The struggle against human oppression is the struggle between memory and forgetfulness" Unquote - Discussed below are some significant landmarks in Public Health interventions globally.

\section{Plague and Quarantine}

The practice of separating people with disease from the healthy populations is an ancient one, with both biblical and koranic references to the isolation of lepers. The term quarantine dates from the late $14^{\text {th }}$ century and the isolation of people arriving from plague infected areas to the port of Ragusa for a period of 40 days. Such public health measures became international subsequently.

\section{Cholera and Sanitation}

The physician John Snow's famous work on cholera notably during the 1854 epidemic in London was based on years of careful recording of outbreaks and heated debate as to the causes. His work eventually led to improvements in sanitation in the United Kingdom that reduced the threat of cholera.

\section{Smallpox and immunization}

Smallpox is one of the oldest known human diseases. There is evidence of its existence over 3000 years ago in Egypt. During the 18th century, smallpox killed every seventh child born in Russia and every 10th child born in France and Sweden. Edward Jenner's experiment in 1796 brought hope that the disease could be controlled. Jenners procedure was soon widely accepted, resulting in sharp falls in smallpox death rates. Through the success of the 10 -year global eradication campaign that began in 1967 , the global eradication of smallpox was certified in 1979 . 


\section{Major International Public Health Interventions in the recent past \\ International Sanitary Conference}

At this time period the affluent world mooted a concept of reaching international agreement in sanitation. Accordingly the first International Sanitary conference was held in Paris in 1851 to prepare an International Sanitary code. In 1907 a permanent, international agency was established and named as the office international $\mathrm{d}^{\prime}$ hygiene publique (OIHP). This was the first truly international health organization. O1HP carries out its functions until 1946 when they were taken over by the Interim Commission of the World Health Organization.

\section{Origin of the United Nations \& emergence of WHO}

The term 'United Nations' was devised by President Roosevelt of the United States. The United Nations officially came in to existence on $24^{\text {th }}$ October 1945 with the charter ratified by china, France, Soviet Union, United Kingdom the United States and by a majority of other Signatories.

In February $19461^{\text {st }}$ General Assembly of the United Nations Economic and Social Council adopted a resolution calling for an international health conference which later opened in New York on 19th June 1946. It decided that the OIHP be absorbed and to form World Health Organization. Which came in to existence from $1^{\text {st }}$ September 1948.

\section{The Big Six}

The interim Commission of WHO had recommended to the $1^{\text {st }}$ World Health Assembly, four priority areas for international health work. These were malaria, tuberculosis, venereal disease and maternal and child health. The health assembly added two more namely nutrition and Environmental Sanitation. These priorities came to be known as the "Big Six" and member countries adopted the strategies.

\section{Malaria}

The control of malaria was considered as one of the priority programs of WHO because of the very high morbidity and mortality. In 1950-1951 control measures were strengthen with DDT spraying. The first signs of resistance to DDT in anopheles was noticed in 1951 in Greece and in 1965 World Health Assembly suggested a change in WHO policy on Malaria from control to eradication. The DDT based malaria eradication campaigns proved to be a dramatic success in their early stages. The campaigns reached their pinnacle of success in the mid 60s after which the situation began to deteriorate.

\section{Tuberculosis}

In addition to malaria, tuberculosis among communicable diseases was the most pressing problem and given very high priority. With the discovery of Streptomycin and Isoniazid, it became possible to use those drugs in Public Health Control Programmes. MDT and DOTS strategies are successfully introduced to prevent and control of TB. Now multi drug resistance on HIV TB co infections has emerged as new problems.

\section{Leprosy}

Leprosy is probably the oldest recorded disease in South East Asia having been mentioned in Rig Veda sometime in $1400 \mathrm{BC}$. It was highly prevalent in many countries of the region including Sri Lanka in the recent past. As a solution, WHO has initiated leprosy control programmes in member countries and Sulfur therapy was introduced.

Introduction of dapsone for the treatment of leprosy, made a change in the strategies of the leprosy control programme. In early $1980 \mathrm{~s}$, a more effective new treatment regimen of multi-drug therapy (MDT) was introduced and. Combined with intensified surveillance of new cases, was a dramatic decline in the number of leprosy cases in the countries was observed.

\section{Venereal diseases}

Venereal diseases earlier used to be treated with mercury compounds for a prolonged period. This let to saying "Two hours with Venus and two years with mercury". With the development of the long-acting Penicillin in 1948 and Its effectiveness in the control of syphilis, the countries in the region have initiated mass campaigns against venereal diseases. This has resulted in dramatic decline in the incidence of new syphilis infection since 1950.

\section{Emergence of Dengue Haemorrhagic Fever}

Dengue fever has been reported in South East Asia and Western Pacific regions since $19^{\text {th }}$ century. But in 1953 a new haemorrhagic form of the disease appeared first time in Philippines and the $1^{\text {st }}$ epidemic was reported in 1958 in Bangkok with a CFR of 10\%. In 1976 WHO identified DHF as one of the priority problems in the region and taken further action on controlling the disease. These actions include establishment of collaborating centres for research on Immuno-pathology of DHF, Dengue Vaccine Development and establishment of Aëdes Research Unit in Thailand. Support was also given for studies on A. aegypti in Indonesia and for the development of rapid diagnostic techniques in the WHO Collaborating Centre in Virology at the National Institute of Virology, Pune, India.. Epidemiological studies on dengue fever, dengue 
haemorrhagic fever (DHF) and dengue shock syndrome (DSS) were also supported in Indonesia, Myanmar, Sri Lanka and Thailand.

\section{Expanded Programme on Immunization}

WHO has taken strong initiative in eradication of Small Pox from the planet in 1958. Last case of Small Pox in the world was reported in Somalia on $26^{\text {th }}$ of October 1977. The $33^{\text {rd }}$ World Health Assembly, on the $18^{\text {th }}$ day of May 1980 declared that the world is free from Small Pox which was a most devastating disease in the $20^{\text {th }}$ centaury.

In identifying the fact that diphtheria, pertussis, tetanus, measles and Poliomyelitis, in particular was rapidly reaching epidemic proportions, the WORD Health Assembly in 1974 called on WHO to intensify its activities pertaining to the development of immunization programmes. This resolution formed the basis for the establishment of the WHO Expanded Programme on Immunization in 1977.

\section{Diarrhoeal Diseases}

The Control of Diarrhoeal Disease (CDD) programme was launched by the WHO in 1979 and ITS main aim is to reduce the mortality and morbidity from diarrhoeal diseases and their associated effects particularly malnutrition in infants and young children.

Oral Replacement Therapy was introduced by the WHO as a solution to dehydration caused by diarrhea. The effectiveness of ORT in reducing mortality was unmatched in its simplicity and accessibility to even the poorest families

\section{Iodine Deficiency Disorders}

There was a high prevalence of iodine deficiency disorders in the countries of the Region. These include goitrous enlargement of the thyroid glands. still births. abortions. congenital anomalies and endemic cretinism. The World Health Assembly, in 1990, decided that WHO should aim at eliminating iodine deficiency disorders in all countries by the year 2000.Universal Salt Iodization was introduced as one of the key measures in controlling IDDS.

\section{Emerging infectious diseases}

For the past 50 years, WHO and its Member States have initiated battle against infectious diseases. As a result of this, smallpox, has been eradicated and diseases like neonatal tetanus and leprosy were eliminated. However, with the world becoming a "global village" as a result of extensive travel and trade, and because of the increase in antibiotic resistance, the hopes of the 1980s regarding the eradication or elimination of most infectious disease' are changing fast. Diseases such as malaria and tuberculosis, once thought to have been controlled, threaten the lives of millions of people in the Region. Plague and kala-azar, which were on the verge of eradication, have resurfaced. New diseases, such as a new strain of cholera, and HIV infection, are spreading rapidly in some countries of the Region.

\section{Disaster preparedness}

Many of the great natural disasters in history have occurred in the South-East Asia Region. In addition, there are manmade emergencies such as explosions, chemical pollution, armed conflicts, and ethnic and other civil strife. WHO's involvement in emergencies and disaster relief dates from its inception in the early years. Later, WHO's policy shifted to the promotion of preparedness at the country, regional and global levels. WHO has assisted Member countries in strengthening national capacities for disaster preparedness and response.

\section{Essential drugs}

In collaboration with WHO, countries have established national' essential drugs lists and mechanisms for updating them. The trend is towards ensuring adequate supply of essential drugs for primary health care. Most countries have also strengthened their distribution system to ensure availability of essential drugs at health posts and at the first referral level. Some countries have established and strengthened facilities for the production of essential drugs and introduced the concept of Good Manufacturing Practices (GMP).

\section{Vision 2020 "The Right to Sight"}

WHO statistics show that there are 45 million people who are blind worldwide and 124 million and 134 million suffering from low vision and retroactive errors respectively. $90 \%$ of those people are living in developing countries. $75 \%$ of the blindness in the world is either preventive or treatable, yet millions of men and women and children all over the world remain blind. In 1999 WHO has instituted a joint programme with APB as a global initiative for the elimination of avoidable blindness by year 2020. It has been captioned "Vision 2020" the "The Right to Sight": and intends to raise awareness and mobilize resources.

\section{WHO initiative in Preventing Diseases Through Healthy Environment}

How much disease can be prevented through healthier environments is a question lies at the heart of our global efforts address the root causes of ill health through improved preventive health strategies using the full range 
of policies interventions and technologies in our arsenal of knowledge. Acting together on the basis of coordinated health environment and development policies member countries can make a real difference in human well being and quality of life.

\section{Primary Health Care and Health for all by 2000}

The concept of primary health care can be traced back to 1937 international conference held in Indonesia. The recommendation made at the conference fore shadowed those made at the international conference on primary health care at Alma-Ata nearly 40 years later.

The concept of primary health care was at first essentially an expansion of the ideas contained in the concept of basic health services. But in the Alma-Ata conference it went beyond that provision and provided a political dimension to primary health care. The principals of primary health care philosophy are equity, community involvement, appropriate technology and multi sectoral approach.

\section{Revitalizing Primary Health Care}

Year 2008 marks both the 60th birthday of WHO and $30^{\text {th }}$ anniversary of the declaration of Alma-Ata on primary health care in 1978. While our global health context has changed remarkably over six decades the values that lie at the core of the WHO consultation and those that informed the Alma-Ata on primary declaration have been tested and remain true. Yet, despite enormous progress in health globally, our collective failures to deliver in line with these values are point fully obvious and deserve our greatest attention. WHO initiative in revitalizing primary health care includes reforms in universal coverage, service delivery reforms, public policy reforms and leadership reforms.

Ladies and gentlemen in brief the interventions implemented by WHO over last six decades had magnificent impacts in achieving highest attainable levels of health globally.

\section{Health development of Sri Lanka}

As we recapitulate our achievements in the field of health over the past sixty years after attaining freedom from the shackles of foreign domination over almost four and half centuries under the Portuguese, Dutch and British, it is pertinent that we look back to the systems of health that prevailed prior to the onset of foreign domination. The ayurveda system of medicine introduced from India was predominantly practiced among the inhabitants of this island. Before introduction of Ayurvedic system with Buddhism in $300 \mathrm{BC}$ historical evidence confirmed a presence of a sophisticated system of health care known as
Deshiya Chikithsa often based on herbs and medicinal oils, for many centuries in Sri Lanka.

\section{Historical Background}

In the early British period the military controlled the health institutions. The creation of the Civil Medical Department in 1858 can be considered as the beginning of the Health service in Sri Lanka. Initially, preventive medicine was confined to measures aimed at preventing the spread of major communicable diseases, smallpox, plague and cholera. It was only in 1912 that preventive health was given due recognition when a Sanitary Branch of the Civil Medical Department was established. The achievements of the Civil Medical Department which existed for 90 years were considerable. At its creation in 1858 , there were only 8 hospitals in the country. Shortly before the British left, the tally was 183 hospitals (including 45 rural hospitals, 240 central dispensaries, 176 branch dispensaries and 453 visiting stations).

The concept of establishing campaigns was initiated by the Rockefeller Foundation which was the first international organisation to assist Sri Lanka's health services. It began its operations in 1915 with the object of controlling hookworm disease.

\section{Health institutional development}

Health Manpower in quality, quantity and appropriate distribution is critically important for the efficiency and effectiveness of the health service. The establishment of the first medical college in 1870, the Sri Lanka Medical Association in 1887, the Colombo General Hospital (1855 - 1860), De Soyza Lying in Hospital in 1880, the Lady Havelock Hospital in 1885, the bacteriological Institute (the present Medical Research Institute) in 1900, the first Nursing School in 1878 and the Kalutara Health Unit (the present National Institute of Health Science) in 1926 were some landmarks in health manpower and institutional development during the colonial period.

\section{Public Health Services}

The establishment of the Sanitary Branch of the Civil Medical Department under a Sanitary Commissioner in 1913, saw the early beginnings of the Public Health Services. Sanitary Officers were appointed to control of infectious diseases and epidemics, bazaar sanitation, and sanitation of urban, rural estate areas. Whilst the general public health activities became the responsibility of Medical Officers of Health (MOH), Specialised Campaigns for the control of diseases were established from time to time. 


\section{Vaccine-preventable Diseases}

Sri Lanka has a history of immunisation against vaccinepreventable diseases that dates back to the 19th century. The success story of immunisation in Sri Lanka started in 1886 and continues to this day.

It is interesting that all activities leading to the present high level of immunisation commenced after the declaration of independence. A streamlined, organised programme was set into motion only in 1978 with the introduction of the Expanded Programme on 1mmunisation (EPI). This programme has received assistance from the World Health Organisation (WHO) and United Nations Children's Fund (UNICEF), as well as other nongovernmental organisations. The results of the immunisation programme are seen in the decline in vaccinepreventable diseases.

\section{Health Financing}

With a population of 20 million and GDP per capita of just over US\$2,000, Sri Lanka is a lower-middle-income country. The country is predominantly rural, with only 20 percent of the population living in urban areas. Total health spending - at US $\$ 43$ per capita-is about 4.3 percent of GDP, below average for its income level. Government spending on health is about 8.4 percent of the overall budget. Sri Lanka's population health indicators are better than those of comparable income countries. In 2004, life expectancy was 75 years, and the infant mortality rate was 12 per 1,000 live births. In 2005 , the number of physicians and hospital beds per 1,000 was 0.55 and 2.9, respectively, higher than in comparable income countries.

On the whole, Sri Lanka has achieved enviable results in its health sector. Sri Lanka was and remains a high performer in health status terms, with better health indicators than other low-income and low-middle income countries. Mortality rates are low and continue to decline at above average rates in comparison with other comparable countries. Fertility is already below replacement levels and life expectancy projected to reach US levels by 2020 . Leprosy and filariasis are eliminated as the $1^{\text {st }}$ country in South East Asia and the national immunization programme against 10 communicable diseases has been quoted as the best in the region and one of the finest in the world. Cardiovascular diseases, cancer, mental illnesses, accidents and malnutrition are on the increase. Malaria, tuberculosis, respiratory illness, diarrhoeal diseases and rabies are still public health problems that tend to persist. HIV/AIDS, Hepatitis B, JE and dengue haemorrhagic fever are challenging situations.
All these outcomes strongly suggest that Sri Lanka is an exception and outlier in provision of health care with low per capita health expenditure among all developing countries in the world. However it appears that to face the present challenges the health system needs to undergo incremental changes as well as system reforms. As such I intend to elaborate the re orientation of the health services to include process reengineering and reforms in order to face those challenges successfully.

\section{Way Forward}

On the whole globally, people are healthier, wealthier and live longer today than few decades ago. If children were dying at 1978 rates, there would have been 16.2 million deaths globally in 2006. In fact there were only 9.5 million such deaths. This shows progress is possible. It can also be accelerated. There have never been more resources available for health than now. The global health economy is growing faster than Gross Domestic Product (GDP), having increased its share from its $8 \%-8.6 \%$ of the worlds GDP between 2000-2005. In absolute terms, adjusted for inflation, this represent a $35 \%$ growth in the worlds expenditure on health over 5 years period. However there are other trends that must not be ignored. First the substantial progress in health over recent decades has been deeply unequal. _Secondly aging and effects of its ill managed urbanization and globalization accelerates worldwide transmission of communicable diseases and the increase of the burden of NCD. Thirdly health sector remains massively under-resourced in many countries. Forth unregulated commercialization is accompanied by blurring of the boundaries between public and private sectors, while the negotiation of entitlement and rights is increasingly politicized. In many regards, the responses of the health sector to changing world have been inadequate.

\section{Health challenges in Sri Lanka}

Despite long list of successes in the health sector, Sri Lanka is forced with an extended health agenda demanding increasingly more resources. Evidence suggests that the immediate challenge to be addressed for Sri Lanka is to sustain the efforts and successes. Since Sri Lanka is on a higher base now, any incremental benefit from now on ward require higher incremental cost. The main challenges health system in Sri Lanka facing now are,

1. Investing in health

2. Attaining millennium development goals

3. Life style diseases

4. Taking Sri Lanka towards global best 
5. Strategic health plan for Sri Lanka to address

I. Organizational changes of health care

II. Health system challenges

III. Poor governance and performance monitoring

IV. Aging population

V. Emerging diseases

\section{Investing in Health}

Health spending is justified for two reasons as an investment and as promotion of welfare. Health is an essential input to produce human capital ultimately resulting in improved economic productivity.

Diseases impede economic growth and development in three ways. First, avoidable diseases reduce number of years of healthy life expectancy. Second, societies with high infant and child mortality rates have higher rates of fertility. Large number of children restricts the ability of the household to spend on the health of each child. Third, the high prevalence of diseases also undermines industries returns to investment as they are required to spend more resources to keep their workers fit.

Similarly it seams that 'wealth is health' because wealthy nations are found to be healthy too. Analysis of GDP per capita and life expectancy at birth in 70 countries reveals that life expectance increases with GDP percapita and stabilizes at about 10,000 USD.

In Sri Lanka reasonably good economic conditions after independence permitted the expansion of health care facilities. About 7\% of GDP was spent of health, education, housing and food. Health alone received $2.5 \%$ of GDP. The combined spending on health, education, housing and food increased to $10.5 \%$ of GDP from 1961 to 1965 . The expansion and the improvement of the health care infrastructure was largely responsible for the decline in morbidity and improved health status. Although higher growth of economy resulted in higher investment in health till 1960s and benefits accrued were quite apparent, the links appears to have been a short term affair and disappeared afterwards. In other words further growth of the economy did not favour a higher government spending on health in Sri Lanka.

JICA EBM (evidence based management) study has clearly shown that with the increasing elderly population and out of proportion emergence of NCD in Sri Lanka the budgetary allocation on health has to be increased by about three fold by 2015 . Hence it is essential for the government to spend more on health so as to enhance health and economy and take Sri Lanka towards the global best in investing in health.

\section{Achieving Millennium Development Goals}

Sri Lanka is yet to address five out of eight millennium development goals before 2015. Eradication of poverty, poverty reduction emerges as the top most priority. Sri Lanka articulated a poverty reduction strategy in 2001 which focused on restoring peace and economic growth in the country.

According to MDGs, Sri Lanka has to bring child mortality rate down to 7 per 1000 live births. Sri Lanka should aim at the global best of 3 per 1000 live births. The possible route to achieve this is the reduction of perinatal mortality, low birth weight and child malnutrition. More resources, including high tech equipment, human resources and advanced technology needs to be allocated for this.

\section{Taking Sri Lanka towards global best}

Despite the phenomenal successes, it is appropriate to place Sri Lanka in a global context in order to know where the country stands in terms of health achievements. This will help her to plan the future priorities, so we can move ahead rather than sinking itself in complacency. Sri Lanka has some distance to traverse before she catches up with the world's best. For instance, life expectancy at birth, though high still fall below the best achieved in the world by $12 \%$. Similarly $80 \%$ improvement is possible in reducing IMR, under five mortality, MMR, TB and malaria deaths.

\section{Health care system as an engine of health development}

As identified MDGs (poverty in particular), lifestyle disorders, ageing, and health system defects as the major priorities requiring immediate attention during the next decade. Among the four, the first three are welfare issues with implications for health whereas the last one is the health care system issue. More specifically, it explains how the health care system can act as an engine for the progress of health. Efficient macro- organization ensures adequate funding for health care which, in turn, results in efficient public sector provision of health care. On the other hand, efficient public provision avoids wastage and enhances the resource availability which is a prerequisite for the efficient organisation of health care. All these three positively influence health outcomes, especially for the disadvantaged populations.

\section{Strategies identified by national policies}

Sri Lanka falls short of the global best by 12.2 per cent in life expectancy, 35.3 per cent in morbidity, and 81.3 per cent in IMR. Poverty is also unacceptably high in Sri 
Lanka. Regression results indicate that every percentage increase in per capita GDP results in a significant increase in life expectancy. Nevertheless, given the fact that life expectancy in Sri Lanka has already reached a very high level, it would require a very high increase in per capita GDP to raise the life expectancy by one year.

Three policy documents were released during the previous decade. National health Policy 1996, Presidential Task Force 1997 and Health Master Plan 2003 are the three major policy initiatives of the government thus far. Enhancement of health care resources, comprehensive health care that includes private sector, decentralization, recognition of service provision performance appraisal system, and quality of care are the key strategies identified by these policy documents.

Macro organizational structure of health care system affects the efficiency and quality of health services. In structuring macro-organization for health care, the fundamental question is how to divide the complex functions of different organizations and make them accountable in achieving societal goals. At present, services are concentrated at higher level while the lower level institutions operate without even the basic minimum facilities. The present organisation does not help to address the problems of the poor and elderly. An issue that has to be addressed through macro organizational structure is how to efficiently and equitably organise primary, secondary. and tertiary care services.

In Sri Lanka, given the disparity in health care loaded in favour of urban areas, it is important to move the health care system (government and private) close to the disadvantaged (estate. rural and old age) populations. One of the strategies available to the government to serve the poor and the elderly health is to split the outpatient and inpatient care services in the country. All the outpatients (whether they hail from urban, rural, or estate) should receive a uniform quality of care. For this purpose, it necessary that all the minimum diagnostic and curative facilities should be made available at the outpatient centres. The most common illnesses can be diagnosed and treated at the outpatient level, complicated diseases may require specialists and/or inpatient services, while the most complicated and serious illnesses may require tertiary care. Geriatric care, care for non-communicable diseases, and treatment follow up should he part of outpatient services.

Conditions that would be treated as outpatient and inpatient should be defined clearly and announced to the people through a citizen charter so that people can easily choose the specific institutions for appropriate care. Only' those patients with referral from outpatient centres or those with conditions ( severe injuries. for instance) defined as requiring inpatient care should be seen in the inpatient facilities. Patients once discharged from the inpatient facilities will be referred back to the nearest (to the patient) outpatient institution. Facilities required for such follow up such as drugs should he made available in the outpatient centres.

The split of institutions requires commencing new outpatient institutions in urban areas, reclassification of already existing health care institutions, and reallocation of man power. equipments and other facilities. Private sector and the traditional system of medicine should be an integral part of all these classifications. Each level of government health care institutions must be provided with autonomy and incentives adequate enough to deal with local emergencies and needs.

One of the major drawbacks of the government health care system, which the private sector tries to cash in, is that the government institutions are open only during specified times of the day. People are forced to use the private sector if they fail to make it to the government centre within the specified time. In order to overcome this drawback, government can operate late clinics in government institutions to cater to the demand arising after the office hours. The late clinics, to be charged a fee equivalent to 50 per cent of the private consultation fee, can be staffed by either government or a private doctor(s) on a fee sharing basis.

\section{Human resource development and distribution}

At present, the size and the quality of the health manpower are inadequate in many areas, especially in rural and estate areas. At the same time, there is excess manpower in some urban government institutions. Regarding the size, some sort of balance between the doctors, nurses and paramedics needs to be worked out and implemented.

An increase in the number of physicians over and above the combined needs of the government and non-government sectors might result in supplier induced demand on physician services. Economic theory predicts that an increase in supply of physicians should reduce the price of services. But in the health sector, an increase raises the prices. An increase in medical school admissions would increase the number of physicians, but also expand the number of specialties and specialists. In turn, it transforms the medical labour market and modality of medical treatments and Increases the price and quantity of services delivered, thus resulting in Increases in overall health care costs. 


\section{Recommendations}

I. Increase government spending on health at least 2.5-3.0 percent of GDP. Private spending would continue to be about 1.5-2.0 GDP so that the total expenditure would be 4.5-5.0 of GDP

II. Reduction of out of pocket expenditure below $30 \%$ of total health expenditure

III. Marking efforts to link national policies and the national and provincial budgets so that national policies are reflected in resource allocation.

IV. _ Restructuring of macro-organizational framework to improve efficiency and equity by splitting outpatient and in patient services. Reclassification of existing healthcare institutions and reallocation of resources will enhance equal facilities at out patient services through out the country.

V. Late clinics should be established in government institutions to cater to the demand arising after the office hours. This will reduce out of pocket expenditure for poor people.

VI. Reorientation of preventive and promotive care to cater for many adolescents, elderly population and lifestyle disorders. Budgetary allocation to preventive health should be increased at least to $20 \%$ of total health budget.

VII. Rationalization of manpower (both size and skills) required in each level institution.

VIII. Periodical performance appraisal of healthcare institutions against their specified objectives and focused on improving quality and good governance.

IX. Establishment of a national health commission to deal with all the health policy matters and healthcare investments both public and private sector.

X. Sri Lankan health system should not only confine to revitalization of primary healthcare and attaining Millennium Development Goals but should be focused on moving towards global best.

In conclusion Sri Lanka is known as a country with a modest economic growth but phenomenal health achievements. The successes at the health sector in Sri Lanka are often commended globally and have been well documented. But it is also the reality that Sri Lanka is now facing new and more formidable challenges. However, the government commitment to maintain its cherished principle of high quality public sector and free healthcare service provision will not be compromised at any cost. Therefore introduction of innovative schemes of financing, reorganization and reorientation of health services, higher investment in health, increase allocative efficiency towards preventive health care, enhancing public sector efficiency will definitely ensure the complete light generated by government vision to guide us along the bumping local and global health development road. 